\title{
Entusiasmo, temores, indiferença: \\ o México na correspondência diplomática brasileira $(1919-1959)^{1}$
}

Regina Crespo*

\section{Resumo:}

Neste artigo se analisa a correspondência enviada ao Ministério de Relações Exteriores do Brasil por seus representantes no México, de 1919 a 1959. Entre os temas que os diplomatas analisaram durante o período, destacam-se a Revolução mexicana de 1910, que alguns consideraram um movimento legítimo e outros, um exemplo que o governo brasileiro precisava combater; a problemática e contraditória relação entre a Igreja e o Estado no México, geradora de trágicos conflitos como a Guerra cristera; e o visceral nacionalismo mexicano, assumido por vários diplomatas como uma comprovação do caráter bárbaro do povo e dos governantes do país. O relatório que Leopoldo Collor enviou ao Itamaraty, em 1959, e as cartas e ofícios reservados escritos por Abelardo Roças, durante os anos 1930, comprovam o importante papel que a correspondência diplomática cumpriu na orientação das relações do governo brasileiro com o mexicano no período e demonstram que brasileiros e mexicanos compartilham, desde então, uma agenda errática, feita de aproximações e conflitos, permeada por uma permanente e latente competição.

Palavras-chave: correspondência diplomática; relações diplomáticas Brasil-México; Abelardo Roças; Leopoldo Collor

\begin{abstract}
:
This article analyzes the correspondence sent to the Ministry of Foreign Affairs of Brazil for their representatives in Mexico, 1919-1959. Among the topics that diplomats during the period analyzed, we highlight the Mexican Revolution of 1910, which some considered it a legitimate movement and others, an example that the Brazilian

\footnotetext{
1 Este texto se insere em uma pesquisa mais ampla sobre as relações diplomáticas entre o Brasil e o México, que contou com o apoio dos programas de fomento à pesquisa da Dirección General de Asuntos del Personal Académico (DGAPA) da UNAM, instituição a que a autora agradece.

* Centro de Investigaciones sobre América Latina y el Caribe de la Universidad Nacional Autónoma de México
}

Revista Eletrônica da ANPHLAC, n.14, p. 43-61, jan./jun. 2013.

http://revista.anphlac.org.br/index.php/revista 
government had to combat, the problematic and contradictory relationship between Church and State in Mexico, generating tragic conflict as the Cristero War, and the visceral Mexican nationalism, assumed by many diplomats as a proof of the barbaric character of the people and the rulers of the country. The report sent to the Foreign Ministry Leopoldo Collor in 1959, and the cards and reserved letters written by Abelardo Roças, during the 1930s, demonstrate the important role that diplomatic correspondence fulfilled in guiding relations with the Brazilian government in the Mexican period and show that Brazilians and Mexicans share, since then, an agenda erratic, made approaches and conflicts, permeated by a permanent and latent competition.

Keywords: diplomatic correspondence; diplomatic Brazil-Mexico, Abelardo Roças; Leopoldo Collor.

Em fevereiro de 1959, por solicitação do Ministério de Relações Exteriores do Brasil, o embaixador Carlos Martins Thompson Flores enviou ao Palácio do Itamaraty um relatório de quase cem páginas datilografadas sobre a situação política mexicana, de autoria de Leopoldo Collor, filho do célebre ex-ministro do trabalho de Getúlio Vargas, Lindolfo Collor, e tio do futuro presidente da República, Fernando Collor de Mello².

A primeira asseveração do autor foi a seguinte: "no México, mais que em qualquer parte, a atualidade tem suas raízes mergulhadas no passado" ("Introdução", p. A). Ao pretender construir um quadro abrangente do sistema político mexicano, Collor descobriu que só poderia fazê-lo recorrendo à história. Para entender a predominância do partido oficial na vida política mexicana, as características da autoridade presidencial, o nacionalismo, a questão religiosa e a política externa, temas que permaneciam candentes em 1959, seria necessário entender as suas origens. "No México, o passado está presente em suas instituições e na sua vida cotidiana", concluiria o brasileiro ("Introdução", p. B).

De que passado falava Leopoldo Collor? Em que circunstâncias e por que esse passado permaneceria tão presente no presente mexicano?

\footnotetext{
2 Leopoldo Collor, Relatório sobre Política Mexicana, Documento anexo ao ofício enviado por Thompson-Flores ao ministro das relações exteriores Francisco Negrão de Lima. México, 17 de fevereiro de 1959. Arquivo Histórico do Itamaraty (AHI), pasta 32/5/12. Todas as referências a este documento serão indicadas no corpo do texto, com o número da página.
}

Revista Eletrônica da ANPHLAC, n.14, p. 43-61, jan./jun. 2013.

http://revista.anphlac.org.br/index.php/revista 
Para responder a estas questões, Collor lançou mão da periodização com a qual os historiadores dividem a história mexicana: Conquista, Colônia, Independência, Reforma e Revolução. Ao retomar o passado, o autor detectou alguns temas importantes que já haviam surgido a partir da conquista do império asteca por Hernán Cortés e que culminaram na etapa revolucionária. A Revolução, segundo Collor, havia marcado o fim de uma longa era na vida política do país e o começo de outra que, iniciada em 1910, não tinha, em 1959 -como ainda não tem- uma data oficial de conclusão.

Para preparar o seu relatório, Collor utilizou fontes primárias e secundárias. $\mathrm{O}$ trabalho, segundo o seu autor, "mais do que uma opinião pessoal, refletiu o critério sedimentado da Embaixada do Brasil” ("Introdução”, p. B). Sua principal fonte de informação foi, portanto, "a experiência da Embaixada, concretizada em inúmeros ofícios à Secretaria de Estado" (p. C). Collor se baseou nas opiniões manifestadas “com insistência" pela Embaixada do Brasil no México em comunicações oficiais sobre vários dos temas tratados no relatório. Quanto a fontes secundárias, recorreu a uma bibliografia majoritariamente escrita por pesquisadores norte-americanos, já que os considerava "ainda os que mais objetivamente têm analisado os fenômenos políticos e sociais do México”(“Introdução”, p. C) ${ }^{3}$.

O relatório de Leopoldo Collor é de 1959, o último ano do período de quarenta que constitui o objeto deste trabalho. A análise de sua minuciosa exposição e da correspondência que os embaixadores e encarregados de negócios em missão no México enviaram ao Itamaraty entre 1919 e 1959 nos permitirá saber que tipo de informação chegava ao governo brasileiro para nutrir suas estratégias políticas em relação àquele país ${ }^{4}$. Além disso, também nos ajudará a entender a evolução das relações entre os governos dos dois países em termos políticos e culturais.

\section{Entre a conveniência e a concorrência}

Durante o século XIX, as relações entre os governos do México e Brasil foram formais e esporádicas. As relações econômicas eram mínimas e pouco havia para compartilhar. A inegável admiração das elites brasileiras pelo progresso econômico e pela estabilidade política mantida a mano dura, durante os longos anos em que Porfírio Díaz ocupou a presidência do país, deixou lugar à apreensão criada pela eclosão da

\footnotetext{
3 Collor utilizou, entre outras, a obras de Frank Tannembaum, Worcester e Schaeffer, Baford Parker e William Tucker. Entre os mexicanos, citou basicamente trabalhos de Cosío Villegas e Jorge Castañeda.

4 Este material está depositado no acervo do "Arquivo Histórico do Palácio do Itamaraty", no Rio de Janeiro.
} 
Revolução mexicana e as incertezas dela decorrentes. Os tempos mudariam e o clima político entre os dois países também.

Em 1910, iniciou-se uma etapa longa e difícil para os mexicanos. A partir do assassinato do presidente Francisco I. Madero e do golpe de Estado de Victoriano Huerta, em fevereiro de 1913, a situação do país no âmbito internacional se complicou. Em 1917, já sob a presidência de Venustiano Carranza, Isidro Fabela capitaneou um plano de propaganda sobre as conquistas da Revolução e da estabilidade política do país, a fim de combater a campanha que o governo dos Estados Unidos orquestrava contra o México entre os países da América do Sul.

Até 1922, o Brasil e o México sustentaram suas relações diplomáticas somente com o apoio de legações. Em 1919, o encarregado de negócios Luiz Gurgel do Amaral chegou a ser recebido pelo presidente Carranza, numa deferência com o Brasil que outros presidentes repetiriam ${ }^{5}$. Em 1921, Antonio Feitosa foi enviado como Embaixador Extraordinário à Comemoração da Consumação da Independência do México, quando teve a honra de discursar como Decano dos representantes diplomáticos e de ser recebido pessoalmente pelo presidente Álvaro Obregón em várias ocasiões. No início de 1922 -por uma iniciativa unilateral do governo mexicano- sua legação no Brasil foi transformada em embaixada. Quase um ano depois, o governo brasileiro, que teve que promover sua legação a embaixada devido ao princípio diplomático da reciprocidade, enviou seu primeiro embaixador ao México. Fiéis à sua tradicional política de alinhamento com os Estados Unidos, os brasileiros relutavam em oficializar a mudança, pois preferiam esperar que este país reconhecesse o governo mexicano, o que só aconteceria em agosto de 1923, depois da firma do polêmico Tratado de Bucareli ${ }^{6}$.

Em 1923, Fabela publicou um artigo celebrando a fundação da embaixada brasileira no México como um fato transcendente, que mudaria a orientação da política internacional da América Latina ${ }^{7}$. O mexicano criticava o fato de que vários países sulamericanos já possuíam uma embaixada nos Estados Unidos, mas continuavam mantendo apenas legações nos países vizinhos. O desconhecimento recíproco entre os

\footnotetext{
5 Durante este ano, Gurgel fez um importante acompanhamento da imprensa mexicana, enviando ao Itamaraty uma série de recortes de jornal sobre temas-chave da política externa do México, principalmente seus problemas com os Estados Unidos sobre petróleo e território. AHI, pasta 221/1 /08.

6 O governo dos Estados Unidos praticamente condicionou o reconhecimento ao governo do presidente Álvaro Obregón à firma deste tratado que garantia os direitos de propriedade dos estadunidenses radicados no México e das companhias de petróleo estabelecidas no país.

7 Especial para El Universal por el Lic. Isidro Fabela, "Significación de la embajada brasileña" s. d. (recorte), Régis de Oliveira ao ministro Félix Pacheco, confidencial, 10 de março de 1923. AHI, pasta $221 / 1 / 9$.
}

Revista Eletrônica da ANPHLAC, n.14, p. 43-61, jan./jun. 2013.

http://revista.anphlac.org.br/index.php/revista 
países da região, aliado a uma conduta subalterna à nefasta doutrina Monroe, impedia o surgimento de qualquer iniciativa política de união sub-continental. Fabela defendia a criação de uma diplomacia ibero-americana que protegesse a região do imperialismo yankee. Nesse sentido, o intercâmbio de embaixadas entre o México e o Brasil representava um triunfo, não conjunto, como tentava fazer crer em seu artigo, mas sim exclusivo do governo mexicano, rumo a uma sonhada união ibero-americana que, nas palavras de Fabela, poderia construir, "num futuro mais ou menos distante, a salvação de nossa raça" ${ }^{\circ}$.

Nesse novo contexto que aparentemente se abria, seria necessário fazer as seguintes perguntas: quem lideraria o conjunto dos países ibero (ou latino) americanos na conquista do novo porvir? Quem designaria as pautas de conduta continental em termos políticos, culturais e econômicos? De que maneira e com que argumentos seria possível combater as intervenções do panamericanismo na agenda política dos países latino-americanos, preocupados em manter uma boa relação com o terrível "irmão do norte"?

Perguntas como estas nortearam as relações entre os governos do Brasil e do México entre 1919 e 1959. Mesclando eventuais momentos de entusiasmo com várias situações de temor e desconfiança recíprocos, a decisão de ambos os governos em muitos momentos foi de se proteger frente ao outro, recorrendo a uma prudente indiferença.

O fato de que a iniciativa de aproximação tenha partido do governo mexicano, num momento em que este necessitava conquistar apoio internacional, demonstra que as relações entre o México e o Brasil sempre passaram pelo filtro dos interesses delimitados pelas respectivas agendas nacionais. Nos anos 1920, a diplomacia iberoamericana proposta pelos mexicanos, muito conveniente aos seus próprios interesses, pouco eco encontrou entre os governantes brasileiros. Nos anos 1930, as relações entre os dois países, ainda que sem grandes arroubos, encontraram na diplomacia, e especialmente em dois de seus representantes, o mexicano Alfonso Reyes e o brasileiro Abelardo Roças, um espaço de aproximação mais compreensivo e em certo sentido inclusive afetivo, embora ambos sempre mantivessem uma postura crítica em relação respectivamente ao Brasil e ao México.

8 Idem.

Revista Eletrônica da ANPHLAC, n.14, p. 43-61, jan./jun. 2013.

http://revista.anphlac.org.br/index.php/revista 
O hiato aberto entre o Estado Novo (1937-1945) e o governo de Lázaro Cárdenas (1934-1940) foi importante para equacionar temas relevantes nas respectivas agendas nacionais e projetos continentais do Brasil e do México. Por um lado, Cárdenas procurou apresentar a Revolução mexicana como um projeto passível de ser adotado pelos países do subcontinente rumo à conquista de mais autonomia política e crescimento econômico. A campanha vitoriosa de nacionalização do petróleo e das estradas de ferro fez com que o México recuperasse o seu prestígio no âmbito latinoamericano. Por outro lado, a política externa brasileira, resultado e instrumento de um governo autoritário, difundia aos países vizinhos uma imagem de estabilidade, resultante da própria opção política adotada pelos brasileiros, com o Estado Novo. O nacionalismo de defesa e a união continental, que fundamentavam a plataforma do governo de Cárdenas, representavam para o governo brasileiro, como bem indicavam as comunicações do seu pessoal diplomático no México, um contraponto que punha em cheque o próprio projeto de liderança brasileiro.

Em tal contexto, o embaixador Roças, como representante do governo e dos setores politicamente conservadores brasileiros, dos quais provinha, defendia a divulgação do regime brasileiro entre os países da região como opção frente à anarquia esquerdizante do programa revolucionário mexicano. Ao México "bronco e violento" oferecia a alternativa do Brasil "civilizado e ordenado". Em várias cartas e ofícios ao Itamaraty, algumas inclusive enviadas antes do golpe de 1937, Roças criticava duramente os nefastos efeitos do que denominava o "esquerdismo mexicano" sobre a vida do país e seus riscos para a política continental. Enquanto isso, seu colega Alfonso Reyes acompanhava com atenção e desagrado o crescimento da repressão política no Brasil, que culminaria exatamente no golpe de Estado de $1937^{9}$.

Os anos 1940, ensombrecidos pela Segunda Guerra Mundial, significaram uma arena de conflito para os representantes brasileiros no México. A defesa dos preceitos político-ideológicos do Estado Novo e a necessidade de combater os protestos da esquerda mexicana, capitaneada pelo polêmico líder político e sindical Vicente Lombardo Toledano, contra fatos como a prisão de Luís Carlos Prestes e de outros líderes do movimento de 1935, levaram os diplomatas brasileiros a uma constante crítica ao governo à sociedade mexicana em geral.

\footnotetext{
9 Cf. Alfonso Reyes, Misión diplomática, Secretaría de Relaciones Exteriores/ Fondo de Cultura
} Económica, México, 2001, 2 vol.

Revista Eletrônica da ANPHLAC, n.14, p. 43-61, jan./jun. 2013.

http://revista.anphlac.org.br/index.php/revista 
O fim do Estado Novo e da Segunda Guerra e também a adoção de agendas nacionais menos ideologizadas e mais pragmáticas pelos dois países de alguma maneira atenuaram a desconfiança, transformando-a em uma certa apatia ${ }^{10}$. Ainda assim, em 1959, em plena Guerra Fria, Leopoldo Collor enfatizava, na introdução ao seu relatório, a importância e a necessidade de o governo brasileiro acompanhar a evolução da política interna e externa do México, já que, em suas palavras, “o México deseja[va] ardentemente a liderança política, econômica e cultural da América Latina" ("Introdução", p. B). Além disso, enfatizava a importância que a diplomacia mexicana possuía para a brasileira em assuntos de âmbito continental. As observações de Collor nos levam a confirmar o fato de que a competição entre os dois países sempre influenciou as suas relações. Apesar de muito alardeada, a preocupação dos mexicanos em construir uma unidade latino-americana continuou resvalando em interesses locais e permaneceu aprisionada em uma retórica muito celebratória, mas nem sempre eficaz e consequente. Os brasileiros, por sua vez, menos apegados a este discurso, seguiram buscando outras maneiras, talvez mais pragmáticas, ainda que não por isso mais eficientes, de impor sua liderança no âmbito continental.

\section{Estado versus Nação}

Mas é hora de voltar ao relatório de Leopoldo Collor para analisar, a partir dos elementos apresentados por ele, alguns dos eixos temáticos que estruturaram a visão dos diplomatas brasileiros sobre o México durante todo o período analisado.

Como já vimos, Collor voltou ao passado para explicar o presente e, ao realizar este percurso, chegou a dizer que "o maior problema do México em todos os tempos parecia ser a consolidação da nacionalidade" (p. 2). Segundo ele, o conflito infranqueável entre duas culturas opostas, iniciado em 1519, com a chegada de Cortés, provocara um trauma tão profundo que, até hoje -dizia então- o país sofre as suas consequências.

O problema se arrastou pela época colonial, quando "toda uma nação, antes forte e pujante, orgulhosa e altaneira, passou a ser estrangeira em sua própria terra" (p. 1), e permaneceu depois da independência. Para Collor, a Revolução de 1910 teria representado um "esforço desesperado para consolidar a nação através da consolidação do Estado" (p. 2).

\footnotetext{
10 A presidência de Ávila Camacho, um general ideologicamente menos radical que Cárdenas, também funcionou como um atenuante de desconfianças.
}

Revista Eletrônica da ANPHLAC, n.14, p. 43-61, jan./jun. 2013.

http://revista.anphlac.org.br/index.php/revista 
Estado versus Nação: eis aqui a oposição que funcionou como fio condutor do relatório de Leopoldo Collor e também como substrado de grande parte da correspondência enviada pelos diplomatas brasileiros ao Itamaraty entre 1919 e 1959. Pensar a conformação da Nação mexicana a partir do conflito oriundo da Conquista e pensar no Estado nacional como produto de uma sucessão de guerras que resultaram inclusive em perdas significativas de território ajuda a entender uma série de características e idiossincrasias da sociedade mexicana e de seus sucessivos governos, a partir de 1910. O nacionalismo exacerbado é uma delas. A xenofobia é outra.

Nas páginas que dedicou à análise da Revolução, Collor relataria como o seu caráter nativista foi-se transformando gradualmente em um sentimento antiestrangeiro. A Revolução voltou-se para o passado, valorizou a tradição indígena e combateu a Conquista uma segunda vez. O estrangeiro foi identificado com o Conquistador, e o ideal revolucionário passou a ser o da construção de uma nacionalidade autenticamente mexicana.

No entanto, como Collor percebeu muito bem, essa revalorização simbólica do autóctone teve que encontrar um sujeito apropriado no qual manifestar-se. O mestiço, esta espécie de síntese ideal da multiplicidade étnica do país, transformou-se no agente ativo da Revolução. Segundo o brasileiro, porém, este agente não estava preparado para a responsabilidade de governar e administrar um país profundamente dividido por ódios e ressentimentos políticos. Retirados de seus povoados para o campo de batalha e daí para os postos administrativos, os mestiços, "sem uma filosofia política, sem uma escala de valores, sem conhecimento do mundo ao que eram lançados, se mostraram incompetentes e sucumbiram à corrupção" (p. 27).

Em 1935, durante o chamado Maximato (período em que o México foi governado de facto pelo general Plutarco Elías Calles, Chefe Máximo da Revolução), o embaixador Abelardo Roças chegou a afirmar que a política mexicana era a mais imoral, corrupta e menos escrupulosa da América Latina ${ }^{11}$. Em 1937, a exemplo do que faria Leopoldo Collor, 22 anos depois, Roças também recorreu ao passado para justificar o retrato negativo que apresentava do contexto político mexicano durante a década de 1930. É certo que, segundo ele, a Revolução havia sido justa, dado que "a orgulhosa aristocracia rural, associada a um clero ávido e parasitário, esbanjava as riquezas do país,

11 Abelardo Roças ao ministro Macedo Soares, 8 de julho de 1935. AHI, pasta 31/2/4.

Revista Eletrônica da ANPHLAC, n.14, p. 43-61, jan./jun. 2013.

http://revista.anphlac.org.br/index.php/revista 
sem cumprir os seus deveres com a nação" ${ }^{\prime 12}$. No entanto, o embaixador não se mostrava otimista com relação ao futuro do povo mexicano, que continuava vivendo em graves condições de pobreza e ignorância.

Grande entusiasta e amigo de Lázaro Cárdenas, Roças criticava a inspiração étnica que regia o seu projeto nacional. A glorificação do indígena que Cárdenas estimulava, aliada a um nacionalismo de matiz esquerdizante, levava o brasileiro a considerar que, para Cárdenas, o "Deus nacionalista da Revolução não e[ra], de fato, o grande conquistador Cortés que, com o estandarte de Castilha, criou a nacionalidade mexicana e a incorporou à cultura universal, mas sim o autóctone Cuauhtémoc, o aborígene dominado pelas forças telúricas e entregue ao bárbaro cultor dos sacrifícios humanos"13.

Indigenismo, nacionalismo exacerbado, uma sociedade em que as maiorias não haviam conquistado nenhuma transformação significativa em sua vida cotidiana, nem haviam provado sua competência na conquista de um México "civilizado". Tudo isso servia como uma espécie de pano de fundo para que os diplomatas brasileiros tecessem um diagnóstico pessimista e se apoiassem numa comparação entre o Brasil e o México completamente desfavorável para este.

A já indicada dicotomia entre um Brasil ordenado e um México "bronco", que não aparece de maneira explícita no relatório de Leopoldo Collor, embora se deixe ver sorrateiramente em alguns momentos do texto, foi recorrente na correspondência diplomática brasileira. O relato de vários diplomatas sobre aspectos da vida política e do cotidiano da população resvalaram por juízos de valor que aprisionavam o México num fatalismo sem saída. País de caudilhos e bandoleiros -para citar uma vez mais a Abelardo Roças- $-{ }^{14}$ o México nada mais podia oferecer que um permanente conflito entre políticos e generais, em que a população sempre sairia prejudicada.

Vejamos como esta separação entre Nação e Estado, detectada por Collor como uma espécie de marca de fundação do México, incidiu em duas situações específicas. A primeira delas se refere explicitamente à religião e a segunda, à política.

\section{Igreja versus Estado}

\footnotetext{
12 Abelardo Roças ao ministro Pimentel Brandão, reservado, 11 de setembro de 1937. AHI, pasta 32/2/5 (26 páginas).

13 Idem.

14 Roças ao ministro Mello Franco, reservado, 26 de outubro de 1931. AIH, pasta 32/2/1.
}

Revista Eletrônica da ANPHLAC, n.14, p. 43-61, jan./jun. 2013.

http://revista.anphlac.org.br/index.php/revista 
Não é exagerado afirmar que, no México, a Igreja sempre se interpôs entre o Estado e a Nação. O conflito entre a Igreja e o Estado, gerado ainda na Colônia, exacerbou-se durante a Reforma (1855-1863), quando a separação entre Igreja e Estado se efetivou. A partir de 1917, agravou-se ainda mais. Com a promulgação da nova constituição, o artigo 130, proposto por Carranza, passou a funcionar como uma rígida ferramenta de controle e restrição da ação da Igreja católica no país ${ }^{15}$.

Os representantes diplomáticos do Brasil no México se surpreendiam com a delicada situação mexicana. Por um lado, constatavam a existência de uma população muito religiosa que estava completamente à mercê das ações repressivas de um governo descontente com a influência da Igreja sobre ela e sistematicamente intolerante com a manifestação de sua religiosidade. Por outro lado, notavam e criticavam o fato de que esta população acabou sendo lançada contra o Estado pelos próprios representantes eclesiásticos, quando estes decidiram fechar os templos e culpar o governo por sua decisão. A Igreja mexicana cultivou entre seus fiéis uma incondicionalidade tal que conseguiu forjar soldados dispostos a dar sua própria vida pela causa religiosa, lutando pelo estandarte de "Cristo Rei”. Entre 1926 e 1929, durante a chamada Guerra Cristera, ou Cristiada, o enfrentamento entre governantes que defendiam um Estado laico e uma Igreja que sempre quis ocupar uma posição proeminente na esfera política manchou o país de sangue, com um número impressionante de mortos (as estimativas variam entre sessenta e noventa mil ${ }^{16}$. A memória de conflitos como este continuou contribuindo, ao longo dos anos, para fortalecer a separação entre o Estado e a Nação, ainda que as famosas leis anti-clericais já não fossem postas em execução. A decisão de não aplicálas se deveu a Lázaro Cárdenas que, como observou Collor, percebeu que "o extremo anti-clericalismo que caracterizara os governos revolucionários seria pernicioso para a implementação de seu programa de governo" (p. 63) ${ }^{17}$.

\footnotetext{
15 O artigo 130 (só reformado em 1992, durante a presidência de Salinas de Gortari) retirava a personalidade jurídica das igrejas, tornava propriedade da Nação os bens eclesiásticos, transformava os ministros de culto em profissionais sujeitos às leis e determinava que para ser ministro de qualquer culto era necessário ser mexicano por nascimento.

16 Fiéis em armas desafiaram o exército nacional e batalhas sangrentas tiveram lugar, principalmente nos estados de Jalisco, Colima, Guanajuato e Zacatecas. Depois de quase três anos, a Guerra Cristera acabou, com a capitulação do alto clero, a desilusão dos católicos com o que consideraram uma traição dos próprios padres ao movimento, e a relativa vitória do Estado mexicano, com a elaboração de uma série de acordos informais que definiriam um modus vivendi entre ele e a Igreja.

17 No entanto, as relações diplomáticas entre o México e o Vaticano só foram reatadas em 1992, durante a presidência de Carlos Salinas de Gortari, e o fato foi muito celebrado entre os católicos, que ainda representam a grande maioria da população do país. Desde então, a presença da Igreja católica na vida política e na mídia, que já era grande, aumentou significativamente.
}

Revista Eletrônica da ANPHLAC, n.14, p. 43-61, jan./jun. 2013.

http://revista.anphlac.org.br/index.php/revista 
Durante os anos da Guerra Cristera, os diplomatas brasileiros acompanharam -e desqualificaram- a perseguição do presidente Calles contra a Igreja, e esta indignação não se limitou aos ofícios da embaixada. No Rio de Janeiro, em 1926, o intelectual católico Jackson de Figueiredo liderou uma campanha na imprensa contra o "bolchevismo" do governo mexicano e as ações do "judeu Elías"" o então embaixador no Brasil e futuro presidente do México, Pascual Ortíz Rubio, a ameaçar romper as relações de seu governo com o brasileiro. No entanto, a manifestação pública da ira do embaixador Ortíz Rubio custou-lhe apenas uma reprimenda de seu próprio governo e não ocasionou nenhum conflito diplomático de monta. Este episódio veio a confirmar que as relações diplomáticas entre os governos dos dois países sempre obedeceriam a um prudente pragmatismo. No entanto, também serviu não só para evidenciar o desconforto dos mexicanos com a censura dos brasileiros, como para indicar que tanto os primeiros como os segundos não tolerariam injerências em seus assuntos internos.

Os representantes diplomáticos do Brasil misturavam sua crítica à repressão religiosa no México com a preocupação com o que consideravam a paulatina "bolchevização" do país. Os ofícios e cartas reservados ou confidenciais são muito ilustrativos nesse sentido.

Os embaixadores Antonio Feitosa (1925-1926), Rinaldo Lima e Silva (19261931), Abelardo Roças (1931-1939) e Carlos Lima Cavalcanti (1940-1944), além de alguns encarregados de negócios, como o anticomunista ferrenho Carlos Alvez de Souza (1935-1937), acompanharam o que definiam alternadamente como "bolchevismo" ou como "esquerdismo mexicano", sempre em contraponto com o conservadorismo brasileiro ${ }^{19}$. Por dever de ofício, mas também por convicção, os diplomatas faziam a defesa dos rumos adotados pelo governo do Estado brasileiro, ao qual serviam como funcionários. Contra o "esquerdismo mexicano", que levava o governo a decisões errôneas e estimulava a discordia no país, sempre existiria a alternativa de um governo harmonioso, como o brasileiro, conduzindo uma população satisfeita.

\footnotetext{
18 Vejam-se, por exemplo, os artigos de Jackson de Figueiredo, de 28 de julho a 1 de setembro de 1926, publicados na Gazeta de Notícias. http://www.permanencia.org.br/revista/historia/Dossie/jackson.htm ${ }_{19}$ Embaixadores que estiveram em anos posteriores, como Antonio Camilo de Oliveira (1949-1951), Adolfo Cardoso de Alencaster (1951-1953) e Carlos Martins Thompson Flores (1954-1959), enviaram sistematicamente ao Itamaraty notícias sobre a esquerda mexicana.
}

Revista Eletrônica da ANPHLAC, n.14, p. 43-61, jan./jun. 2013.

http://revista.anphlac.org.br/index.php/revista 
Esta crítica dos brasileiros ao sistema político mexicano abre espaço para a discussão, apontada por Leopoldo Collor, acerca da separação entre Nação e Estado no âmbito específico da política.

\section{O império do Partido}

Ao enviar ao Itamaraty os seus relatórios, os representantes diplomáticos descreviam, no calor da hora e sob os eflúvios de suas próprias concepções ideológicas, o processo que foi paulatinamente culminando no controle pleno e total da vida política do país por um único sujeito: o Partido Revolucionário Institucional, PRI.

Com sabemos, em 1928, nas vésperas de deixar a presidência, Calles articulou a formação de um novo partido, que funcionaria desde a sua fundação como o partido oficial do regime revolucionário mexicano. Durante todos esses anos, os funcionários diplomáticos brasileiros informaram ao Itamaraty não só acerca do peculiar espaço que, sob três distintas denominações, o partido oficial foi adquirindo na vida do país, como também acerca do protagonismo que a figura do presidente foi assumindo sobre ela. No modelo concebido por Calles, a presidência da república constituía o ápice de uma estrutura sociopolítica piramidal, criada para reunir todos os setores sociais sob os propósitos e objetivos revolucionários e, segundo Collor, para institucionalizar a máquina de controle político do próprio Calles (p. 32).

O que seus antecessores puderam observar e comentar no seu dia-a-dia, Leopoldo Collor analisou, em 1959, com o distanciamento crítico que os anos lhe puderam oferecer. Para Collor, a velha ordem que a Revolução havia vencido foi substituída por outra, em que o Partido passou a dominar com autoridade quase absoluta (p. 31). Entre 1928 e 1938, o partido oficial, que então se chamava Partido Nacional da Revolução (PRN), era constituído por três setores sociais: o militar, o agrário e o trabalhista. A partir de 1938, o partido passou a chamar-se Partido da Revolução Mexicana (PRM) e incorporou à sua estrutura o chamado setor popular, através do qual se podiam afiliar todos aqueles que não faziam parte dos três setores anteriormente mencionados (p. 33). Durante a presidência do general Ávila Camacho (1940-1946), o setor militar foi retirado do partido e se fortaleceu o setor popular, principalmente com a formação da Confederação Nacional de Organizações Populares, que, segundo Collor, "proviu o partido de uma estrutura subdividida de acordo com grupos profissionais, intelectuais, juvenis e femininos" (p. 33). A partir de 1946, o partido adotou o nome que mantém até hoje: Partido Revolucionário Institucional (PRI). Com a construção de uma

Revista Eletrônica da ANPHLAC, n.14, p. 43-61, jan./jun. 2013. http://revista.anphlac.org.br/index.php/revista 
estrutura burocrática altamente organizada e compartimentalizada em comitês que abrangiam todos os âmbitos, do municipal ao nacional, o PRI se espalhou por todo o país.

Segundo Collor, em 1959, o PRI dominava a vida política mexicana com poder absoluto. Fora dele não havia nenhuma esperança de sucesso para quem tivesse ambições de êxito político (pp. 37-38). A mística revolucionária do partido era, para o brasileiro, um poderoso elemento de constituição do exacerbado nacionalismo mexicano (p. 38). Além disso, sua ação tão incisiva fizera com que a luta partidária, característica de qualquer regime democrático, desaparecesse e fosse substituída por uma luta de facções no seio do próprio PRI e por uma verdadeira guerra de personalidades. Esta guerra se materializava a cada sexênio durante a sucessão presidencial, dada a prerrogativa garantida ao presidente antecessor de indicar, entre os priistas, o "candidato oficial” e inevitável ganhador das eleições.

Leopoldo Collor ofereceu ao Itamaraty um interessante painel da vida políticopartidária mexicana. Em 1939, a oposição ganhara um partido de centro-direita, com a fundação por Manuel Gómez Morín do Partido da Aliança Nacional (PAN). Apesar de tentar funcionar como uma alternativa ao partido oficial, apenas em 1952 o PAN conseguiu indicar um candidato à presidência da República. Em 1948, surgira um partido de oposição de esquerda, o Partido Popular (PP), fundado por Vicente Lombardo Toledano. Este importante intelectual e líder sindical havia sido muito próximo ao PRI e rompera relações com ele durante a presidência de Miguel Alemán, período em que, segundo Lombardo Toledano, o partido se havia corrompido e traído a Revolução (pp. 39-40) ${ }^{20}$. Também em 1952, o PP lançou um candidato à presidência (o próprio Lombardo Toledano), mas quem acabou sendo eleito foi Adolfo Ruíz Cortines, obviamente indicado por Alemán. Citando a Cosío Villegas, Collor veria na dominação do PRI, “a detenção indefinida do poder por um grupo de homens" (p. 72) ${ }^{21}$.

\footnotetext{
${ }^{20}$ Cf. Embaixada do Brasil ao Itamaraty. Mês político número 5, Outubro, 3 de novembro de 1949. AIH, pasta 32/3/13. Para Collor, "o Partido Popular [era] constituído de elementos predominantemente marxistas, de homens surgidos da Revolução e intimamente convencidos da excelência de seus princípios, incluindo-se entre eles o nacionalismo e sobretudo o anti-imperialismo americano ou russo. Daí a luta do PP contra a Igreja Católica, que considera[va] imperialista à sua maneira e aliada (ainda que pareça incrível) aos EUA" (pp. 65-66). Segundo o autor, o Partido Popular era, então, o mais ortodoxamente anti-clerical e nacionalista no México (p. 66).

${ }_{21}$ Daniel Cosío Villegas, "La crisis de México", em Extremos de América, México, Tezontle, 1949, p. 12.
}

Revista Eletrônica da ANPHLAC, n.14, p. 43-61, jan./jun. 2013.

http://revista.anphlac.org.br/index.php/revista 
Collor completaria o quadro político-partidário nacional com o Partido Comunista Mexicano (PCM) ${ }^{22}$. O brasileiro observou que, apesar de ser uma força política oficialmente presente, desde sua fundação em 1919, o PC era pouco forte no México. A razão estaria, segundo Collor, no fato de que no México, "a demagogia habitual dos partidos comunistas é feita pelo próprio PRI" (p. 40). E o seu diagnóstico sobre o panorama político nacional seria taxativo: "enquanto o partido oficial, o PRI, está fortemente entrincheirado atrás da mística da Revolução, e em torno dela rigidamente unificado, a oposição, desagregada política e doutrinariamente, se dedica a atirar-lhe críticas e a procurar desfazer a sua obra revolucionária" (p. 40).

Ao refletir acerca da influência do comunismo na política mexicana, Collor diria: "é fácil entender que num país como o México, que tem a sua própria Revolução, a sua própria ditadura do partido e sua própria mística revolucionária, o fascínio do comunismo internacional não tenha grande poder de atração” (p. 20). Collor pôde observar como o nacionalismo -que caracterizou a Revolução e foi “'institucionalizado' pelo partido, tornando-se artigo de fé no credo revolucionário" (p. 58)- explicava muito do fechamento da sociedade mexicana em geral com relação ao que vinha de fora. Nas palavras do autor, "todos os estrangeiros, espanhóis como chilenos, franceses como argentinos, americanos como brasileiros, e tudo o que emana deles, são objeto das indiscriminadas suspeitas dos mexicanos" (p. 59). Pois bem, com essa intolerância a tudo o que era estrangeiro e com o fato de que os mexicanos percebiam tudo o que era nacional como superior, não haveria lugar para um "comunismo estrangeiro". A Revolução mexicana que, para orgulho dos nacionais, se dera antes da Revolução russa, teve entre seus méritos o de criar uma espécie de “ 'comunismo' próprio, nacional” (p. 59), que os diplomatas que antecederam a Collor chamaram, como já vimos, de "esquerdismo mexicano".

O balanço final que Collor realizou do sistema político mexicano foi negativo. Suas falhas fundamentais eram precisamente a existência de uma ditadura do partido; a falta de liberdade nas eleições; a "institucionalização" da Revolução; o burocratismo; o surgimento de uma nova "classe", de uma nova "elite de dominação" tanto política como econômica e a identificação do Partido com o Estado (p. 40).

\footnotetext{
${ }^{22}$ Collor incorporou ao quadro político-partidário mexicano a ultraconservadora União Nacional Sinarquista. No entanto, não considerou nem o Partido Constitucionalista Mexicano, fundado em 1951, pelo General Francisco Mújica e outros militares da fase armada da Revolução mexicana, nem a Federação de Partidos do Povo Mexicano, ao qual aquele se juntou para apoiar a candidatura presidencial do general dissidente Miguel Henríquez Guzmán nas eleições de 1952.
}

Revista Eletrônica da ANPHLAC, n.14, p. 43-61, jan./jun. 2013.

http://revista.anphlac.org.br/index.php/revista 
Collor compararia o exemplo mexicano ao dos regimes comunistas. Para ele, os elementos acima enumerados eram resultantes dos processos revolucionários em geral. No entanto, no caso específico do México tais elementos não haviam sido decorrência de um esforço no sentido da socialização, como havia sucedido nos países comunistas, mas sim de um programa de capitalização da economia empreendido conjuntamente pelo partido e pelo Estado (p. 41). A semelhança entre os casos do México e dos países socialistas estaria no fato de derivarem ambos de um esforço de consolidação da nacionalidade através do fortalecimento do Estado (p. 41).

É momento de perguntar se, a partir das colocações de Leopoldo Collor, a consolidação da nacionalidade mexicana teria sido realmente possível por intermédio do fortalecimento do Estado, via a ação incisiva do partido oficial. Se tomamos em conta as observações dos diplomatas brasileiros que, entre 1919 e 1959, escreveram ao Itamaraty acerca do caráter rancoroso e xenófobo da sociedade mexicana e de sua necessidade quase atávica de líderes, poderíamos pensar que sim. O PRI, como partido oficial, conseguiu este feito, ao reunir a chamada "família revolucionária" (uma representação harmoniosa de toda a população, sem distinção de classe), sob as ordens do presidente da República. O "grande patriarca” seria o principal responsável pela condução do povo mexicano por um caminho eventualmente difícil, mas sem desvios, rumo à consolidação dos ideais revolucionários e da grandeza nacional. O partido oficial e o Estado se amalgamaram num discurso belicoso e auto-afirmativo a partir do qual a Nação finalmente se consolidou. Tal discurso se encarregou de difundir e perpetuar um conjunto de símbolos responsáveis pela construção de um ideário comum e de uma orgulhosa mexicanidade.

Ao longo dos quarenta anos pesquisados, os correspondentes brasileiros analisaram o acontecer político, social e cultural mexicano e, em suas cartas e ofícios, foram construindo um diagnóstico negativo da sociedade mexicana. Basearam-se, entre outros elementos, naqueles arrolados por Leopoldo Collor no início de seu relatório: "a predominância do partido oficial na vida política mexicana, a autoridade presidencial, o nacionalismo, a questão religiosa e a política externa". Ao refletir, a partir da análise de acontecimentos pontuais, sobre circunstâncias da política, da cultura e da história do país, os diplomatas opinavam que o Estado mexicano pós-1910 havia sido incapaz de solucionar muitas das contradições que o projeto revolucionário pretendia extirpar. Em tal contexto, o México não representava um modelo a seguir para a América Latina. No entanto, isso não os impedia de considerar o governo mexicano como um forte 
adversário para o brasileiro no âmbito continental. Por isso, nunca perderam de vista os movimentos da sua política externa e sempre acompanharam com atenção sua forte influência nos países centro-americanos. Segundo Collor, por influência do forte nacionalismo, tanto a chamada opinião pública como o própio governo não se preocupavam com questões internacionais que não tivessem consequências imediatas na política interna do país (p. 70). No entanto, a força desse nacionalismo, ao qual a política externa mexicana desmonstrava completa fidelidade, dirigia as ações do governo mexicano também no âmbito da política externa. Ao mesmo tempo em que se desenvolveu uma política externa que funcionava como uma barreira para a defesa do desenvolvimento interno do país contra fatores externos, também se lutou pela hegemonia mexicana na América Latina. Assim, nas palavras do brasileiro, a política externa mexicana não só se dedicou a "defender o país da dominação política, econômica e cultural dos países que ela sabe serem mais fortes, principalmente os Estados Unidos; [...] como a dominar política, econômica e culturalmente aqueles países continentais que ela acredita mais fracos, principalmente da América Central e do Caribe" (p. 74).

Em 1959, ao refletir sobre a conjuntura política mexicana, Leopoldo Collor reconhecia os ganhos da Revolução: “a destruição da sociedade rural eminentemente feudal, da velha oligarquia política, do poder militar; a paz política interna, a valorização do operário e do 'campesino', dos intelectuais e da classe média; e sobretudo a eliminação da violência e do terror na vida de cada cidadão" (p. 31). No entanto, também observava que a oligarquia política havia sido substituída por uma nova, e a velha ordem havia sido suplantada por outra, em que o partido dominava com autoridade absoluta. Collor também notava que, apesar de que a "mística da Revolução domina[va] todas as fases da vida política interna mexicana, frequentemente com espírito oco e demagógico", a irresponsabilidade e a corrupção administrativa continuavam vivas; a alimentação, o vestuário e a habitação do povo não haviam melhorado de maneira significativa e as necessidades básicas da economia mexicana não haviam sido satisfeitas". E concluía que em todos estes pontos a Revolução havia fracassado (p. 31).

De qualquer maneira, para o brasileiro a estabilidade do sistema político mexicano era indiscutível. O PRI, que surgira para resolver as "necessidades ineludíveis do sistema político interno mexicano" e cumprir as promessas da Revolução, que, em 1959, ainda continuavam sendo promessas, havia conseguido associar "a defesa da obra

Revista Eletrônica da ANPHLAC, n.14, p. 43-61, jan./jun. 2013. http://revista.anphlac.org.br/index.php/revista 
revolucionária já realizada com a execução daquilo que ainda esta[va] por realizar" (p. 53). Ao conseguir o apoio unânime da maioria das forças políticas, o PRI pôde manter a sua estabilidade e, consequentemente, a estabilidade da vida política nacional. Como Collor pôde concluir, o PRI conquistara um veredito social favorável e seus prognósticos de que este veredito não se modificaria en um futuro próximo se cumpriram de maneira cabal. A ação do PRI teve como resultado levar a uma identificação autómatica entre a obra revolucionária do partido e a obra revolucionária da nação (p. 53).

\section{Entusiasmo, temor, indiferença}

Seis anos antes de que Collor escrevesse seu relatório, em março de 1953, o escritor Cyro dos Anjos enviou uma carta ao ministro de Relações Exteriores, Jayme Chermont, comentando acerca da inauguração do Curso de Estudos Brasileiros na Faculdade de Filosofia e Letras da Universidade Nacional Autônoma do México $(\mathrm{UNAM})^{23}$. A festa contou com a presença de Alfonso Reyes e José Vasconcelos, os mais célebres amigos do Brasil, além de muitos intelectuais, alunos e professores. $\mathrm{O}$ curso, divulgado por rádio, TV e mídia impressa, parecia destinado ao sucesso e, para ministrá-lo, Cyro dos Anjos recebeu da UNAM o título de "Professor Extraordinário". Além das aulas na universidade, organizou um programa intenso de difusão da cultura brasileira no país. Durante o período de pouco mais de um ano durante o qual coordenou tal programa, Cyro dos Anjos viajou pelo interior do México, dando aulas e conferências. Além disso, foi o responsável pela criação de uma revista acadêmica, Cuadernos Brasileños, que teve três números, e também contribuiu na tradução ao espanhol de vários livros brasileiros de literatura e ciências humanas que o Fondo de Cultura Econômica publicou.

A decisão do governo brasileiro de fazer com que a embaixada promovesse um amplo programa de difusão cultural no México demonstra que, paralelamente à constante preocupação dos representantes diplomáticos em acompanhar a vida política mexicana, e apesar de todas as críticas que os seus relatórios confidenciais e reservados faziam chegar ao Itamaraty acerca do país, seu governo e sua população, havia espaço para o estabelecimento de iniciativas importantes rumo a uma integração mais efetiva entre os dois países.

\footnotetext{
23 Cyro dos Anjos ao ministro Jaime Chermont. Anexo. Embaixada do Brasil ao Itamaraty, Mês cultural.
} Fevereiro de 1953. AIH, pasta 32/4/11.

Revista Eletrônica da ANPHLAC, n.14, p. 43-61, jan./jun. 2013.

http://revista.anphlac.org.br/index.php/revista 
Nesse sentido, outro empreendimento interessante, também levado a cabo por brasileiros alguns anos antes, foi a fundação do Instituto México-Brasil, no Rio de Janeiro, com sede também em São Paulo ${ }^{24}$. Em 1944, Vicente Lombardo Toledano foi recebido ali com todas as honras, não como agitador político, mas sim como importante líder do movimento sindical latino-americano e reitor de uma universidade operária ${ }^{25}$. Este caso serve para mostrar, uma vez mais, que os governos do Brasil e do México sempre conduziram suas relações de maneira pragmática. A iniciativa brasileira de criar um instituto de intercâmbio cultural entre os dois países e a decisão dos seus membros de receber de maneira oficial a uma personalidade até então estigmatizada no Brasil, demonstram, novamente, que as divergências ideológicas não costumavam sobrepor-se a interesses econômicos ou políticos.

A análise da correspondência brasileira, ao longo dos quarenta anos pesquisados, indica que a preocupação dos diplomatas em construir um quadro abrangente da situação política, econômica e cultural do México se desenvolveu em várias vertentes. A atenção com relação à projeção internacional do México e a posição que ocupava no âmbito latino-americano, como já comentamos, nunca diminuiu. Em 1954, o embaixador Thompson Flores acompanhou com cuidado o apoio que o presidente Ruiz Cortines ofereceu ao governo de Jacobo Arbenz e a oposição dos mexicanos à intervenção dos Estados Unidos na Guatemala ${ }^{26}$. Além disso, o brasileiro também anunciou o possível reatamento de relações diplomáticas entre os governos mexicano e espanhol, especulando se esta decisão do presidente Ruiz Cortines representava uma crítica velada aos princípios comunistas de Lázaro Cárdenas e se indicava ou não uma

\footnotetext{
24 Até o momento não foi possível encontrar muitas informações sobre este instituto. Um dado interessante é que o seu presidente, em 1944, era o coronel Luís Carlos da Costa Neto, quem, havia sido indicado superintendente das Empresas Incorporadas ao Patrimônio Nacional, criadas por Getúlio Vargas em 1940. Cf. "Instituto Brasil-México. Homenagem ao Prof. Vicente Toledano, presidente da Conferência dos Trabalhadores Latino-americanos", Correio Paulistano, 11 de março de 1944. FHVLT. Informação hemerográfica, Pasta 14, série de recortes sobre a visita de Lombardo Toledano ao Brasil.

${ }_{25}$ Cf. "Em São Paulo o Sr. Vicente Lombardo Toledano", O Estado de S.Paulo, 10 de março de 1944. Fondo Histórico Vicente Lombardo Toledano (FHVLT). Informação hemerográfica, Pasta 14, série de recortes sobre a visita de Lombardo Toledano ao Brasil. Este fato não deixa de ser curioso, já que, apenas dois anos antes o mexicano teve seu visto de entrada ao país negado. Além disso, desde 1936, precisamente quando começara a se pronunciar a favor da libertação dos presos políticos brasileiros, Lombardo Toledano passou a ter sua ação política acompanhada de cerca pela embaixada do Brasil.

26 Embaixada do Brasil à Secretaria de Estado das Relações Exteriores. Mês político de abril, 3 de maio de 1954, Anexo. AIH, pasta 32/5/2; Mês político de maio, 1 de junho de 1954, Anexo, AIH, pasta 32/5/2. $\mathrm{O}$ apoio incisivo dos mexicanos aos guatemaltecos e a decisão do governo mexicano de receber o presidente destituído como exilado surpreenderam o embaixador, que via aí uma tendência claramente esquerdizante.
}

Revista Eletrônica da ANPHLAC, n.14, p. 43-61, jan./jun. 2013. http://revista.anphlac.org.br/index.php/revista 
mudança de rumos na política exterior mexicana ${ }^{27}$. No mesmo ano em que Cyro dos Anjos e, depois, Aurélio Buarque de Holanda, desenvolviam seu programa de difusão cultural, projetando o Brasil nos ambientes culturais, artísticos e educativos do país, o embaixador, descontente com a política interna e externa mexicana, enviava ao Itamaraty uma análise meticulosa e de teor notoriamente negativo sobre a ação -uma vez mais- de Lombardo Toledano e do Partido Popular no México e nos países vizinhos $^{28}$.

Exemplos como estes são abundantes na correspondência dos diplomatas brasileiros no México. Servem para comprovar que os funcionários diplomáticos, seguindo as determinações político-ideológicas do governo ao qual serviam, procuraram enviar-lhe um conjunto de informações o mais amplo possível. A análise das relações entre os governos do México e do Brasil durante este longo período comprova como o seu trabalho serviu, em muitos momentos, como base para o desenho de uma política especificamente destinada às relações do Brasil com aquele país.

Vizinhos distantes e competidores até certo ponto cordiais, brasileiros e mexicanos têm compartilhado uma agenda de relações errática, permeada por iniciativas de aproximação ao lado de situações de divergência, conflito ou indiferença. A análise da correspondência diplomática ajuda a entender e a explicar estas relações.

Recebido em: julho.

\footnotetext{
27 É necessário recordar que os diplomatas brasileiros acompanharam de perto a evolução das relações entre os governos mexicano e espanhol. Reprovaram a decisão de Cárdenas de apoiar os republicanos e o criticaram quando resolveu receber centenas de exilados espanhóis, depois da vitória de Franco. Ver, por exemplo, Alves de Souza ao ministro Macedo Soares, confidencial, 10 de novembro de 1936. AIH, pasta $32 / 2 / 4$.

28 Na avaliação de Thompson Flores, o líder político e seu partido eram os principais propagandistas do comunismo na América Latina e, ao apoiarem incondicionalmente o governo priista no México, tinham o campo livre para influenciar a política da região. Embaixada do Brasil à Secretaria de Estado das Relações Exteriores. Mês político de abril, 3 de maio de 1954, Anexo. AIH, pasta 32/5/2.
}

Revista Eletrônica da ANPHLAC, n.14, p. 43-61, jan./jun. 2013. http://revista.anphlac.org.br/index.php/revista 